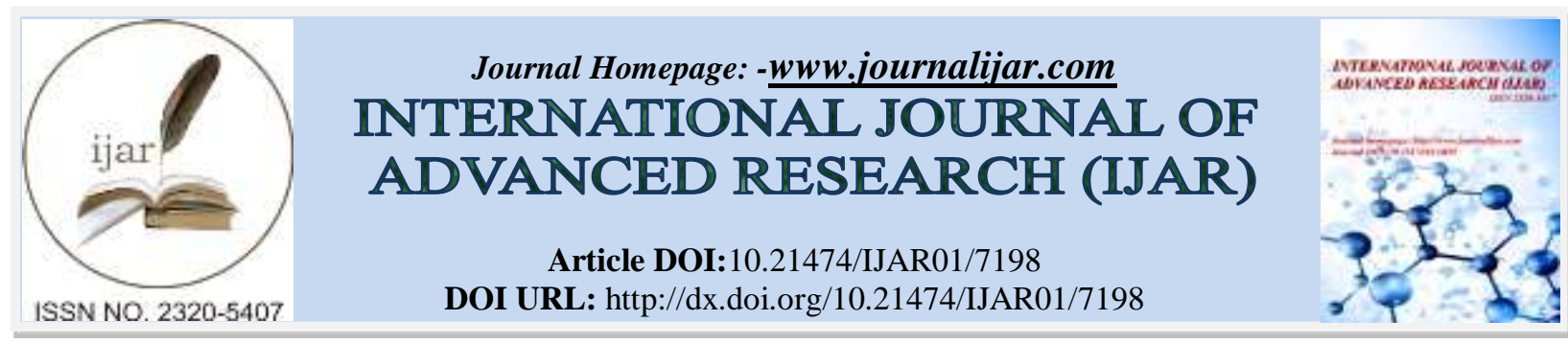

RESEARCH ARTICLE

\title{
CFD SIMULATIONS FOR MIXING BY INTRODUCING SOLID OBJECT IN LID DRIVEN SQUARE CAVITY.
}

B Senthil Rathi, Dr. R Baskaran and N Deepa.

Department of Chemical Engineering, St. Joseph's College of Engineering, Chennai.

\section{Manuscript Info}

Manuscript History

Received: 03 April 2018

Final Accepted: 05 May 2018

Published: June 2018

Keywords:-

CFD, lid-driven square cavity, Reynolds

numbers, mixing.

\section{Abstract}

CFD simulations of the 2D lid-driven square cavity flow are performed for a wide range of Reynolds numbers. The twodimensional square lid driven cavity can be achieved by steady motion of the upper walls. This paper mainly focuses on flow and mixing characteristics of fluids in a Lid driven square cavity by steady motion of both upper and bottom plate. This aims at simulating square 2-D Lid driven cavity flow at different Reynolds number. Also, simulations can be carried out by introducing a solid object (i.e. square block) at different positions in the cavity and streamline patterns can be compared with above case and its mixing characteristics has been studied. The comprehensive features and variations of flow patterns of the flow field under various operating conditions can be computed. The cavity flow is studied as it is a flow which shows very clearly the important aspects of mixing behavior in a creeping flow. The mixing rates can be analyzed in terms of the flow patterns and tracer dynamics. Using CFD, the study of mixing characteristics of fluids based on cavity flow becomes easier and more economic than with the use of experiments. Mixing is relevant where Reynolds number is high and diffusion rate is high.

Copy Right, IJAR, 2018,. All rights reserved.

\section{Introduction:-}

Computational Fluid Dynamics (CFD) has wide applications in areas such as aerospace, automobile and materials manufacturing industries. CFD is attractive to industry since it is more cost-effective than physical testing [1]. Liddriven cavity, with steady velocity of the lid, is one such problem which has been investigated extensively for several years due to many reasons [2-3]. The flow in such cavities is considered to be an idealized representation of several engineering applications such as short-dwell coating, drying operations etc. [4]. It has significant applications in industry, from processing foods and polymers [5] to coaters used to produce high-grade paper, photographic film [6] and in mixing of biological suspensions and blending of viscous fluids, where thermal energy and molecular species transfer are greatly enhanced [7]. Oscillatory box flowwas studied theoretically and numerically [8]. The central portion of the flow motion was observed to be parallel and the results were consistent with their experimental results. The flow within a 2-D closed finite square cavity, driven by a sliding wall which executes sinusoidal oscillation was first treated [9]. The 3-D flow structures in a cubic cavity with an oscillating lid by numerical simulations were analyzed [10]. Theflow visualization experiments were carried out at low $\mathrm{Re}$, in a corotating periodic cavity. The flow was induced by means of continuous and discontinuous motion of the walls [11]. 
The experimental flow visualization study was provided the first direct experimental evidence of the effects of visco-elasticity in the lid-driven cavity problem. In their experiments, they measured the extent of mixing in timeperiodic cavity flows of an ideal elastic fluid [12]. The polymer stresses to understand how elasticity changes the flow kinematics, slowing the primary recirculation vortex and causing the vortex center to shift opposite to the direction of lid motion [13]. The flow of shear thinning fluids in two- and three-dimensional time periodic cavity flows was studied and reported that the overall effect of a shear-thinning viscosity is to decrease the rate and extent of mixing due to a decrease of stretching in the flow, which is the primary route to efficient mixing [14]. Fluid mixing in 2-D and 3-D time periodic cavity flows as a function of rheological fluid parameters was studied. The existence of good mixing regions for Newtonian fluids and bad mixing regions in case of shear thinning fluids was found and determined the mixing efficiency[15-16].

\section{Computational Methodology and Details:-}

The computational simulations were performed using FLUENT 6.2.16. The details involve in obtaining flow and concentration fields are discussed in this section. The 2-D geometries are developed using Gambit 2.1. The grid independence was ensured by meshing the geometry with different spacing between the cells. The quad map type grid with 10000 cells was chosen for 2-D computations for detailed studies. The flow fields were computed by solving mass (Eq. 1) and momentum (Eq. 2) balance equations. For non-Newtonian power law fluids, the stress tensor can similarly be written in terms of a non-Newtonian viscosity $\eta$ (Eq. 3). In general, $\eta$ is a function of all three invariants of the rate-of-deformation tensor D. However, in the non-Newtonian models available in FLUENT, $\eta$ is considered to be a function of the shear rate $\gamma$ only. $\gamma$ is related to the second invariant of D (Eq. 4).A nonNewtonian power law model was chosen. The power law parameters calculated from the rheological measurements was incorporated in the model (Eq. 5) to study the flow. The upper and lower limits on the viscosity are defined for the power law function, (Eq. 6) where and $\eta_{\min }$ and $\eta_{\max }$ are, respectively, the lower and upper limits of the viscosity of a power law fluid. The convective flow terms were discretized using a second order upwind scheme. The boundary condition on the top and bottom plate was imposed. The other faces of the cavity were considered as solid stationary walls. The coupled implicit time formulation was used with second order accuracy.

$$
\begin{aligned}
& \frac{\partial \rho}{\partial t}+\nabla \cdot(\rho u)=0--------(1) \\
& \frac{\partial(\rho u)}{\partial t}+\nabla \cdot(\rho u u)=-\nabla p+\nabla \cdot(\tau)+\rho g-------(2) \\
& \tau=\eta(D) D--------(3) \\
& \left.\gamma=\sqrt{\left(\frac{1}{2}\right.}(D: D)\right)-------(4) \\
& \eta=K \gamma^{n-1}-----------(5) \\
& \eta_{\min }<\boldsymbol{\eta}=\eta=K \gamma^{n-1}<\boldsymbol{\eta}_{\max }----------------(6)
\end{aligned}
$$

Results and Discussion

Lid-driven cavity, with steady velocity of the lid, is one such problem which has been investigated extensively for several years due to many reasons. A schematic representation is depicted in Fig. 1. 


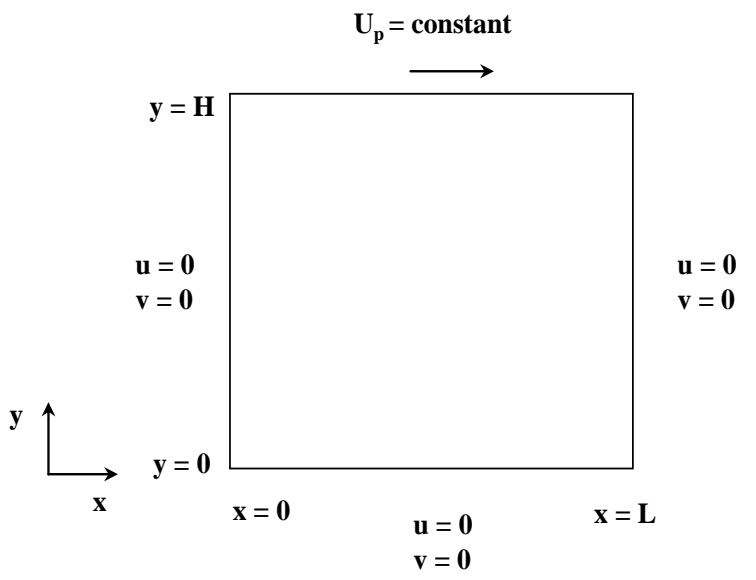

(a)

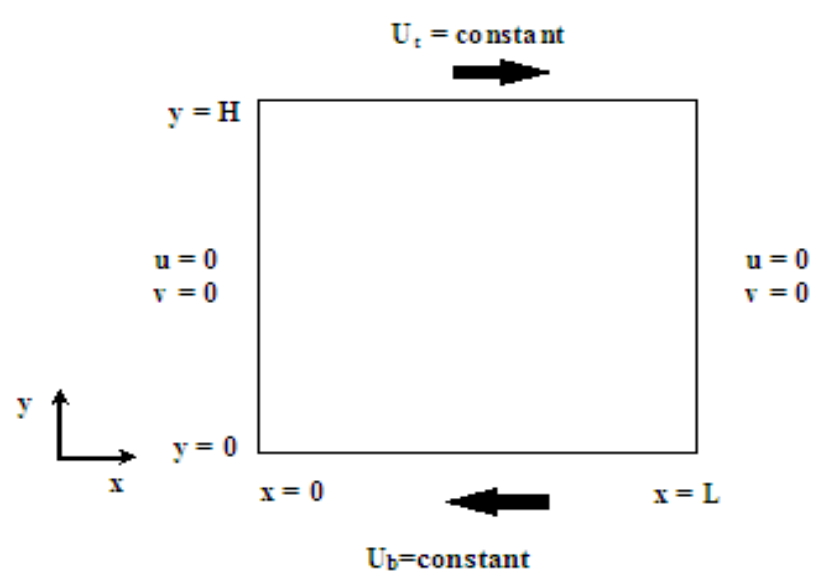

(b)

Figure 1:-Schematic representation of Steady Lid-Driven cavity (a) Top plate moving (b) Top and bottom plate moving

Flow field and Mixing of Non Newtonian Fluid in a Square Lid Driven Cavity Flow:-

Square lid driven cavity box of dimension $50 \times 50 \mathrm{~cm}$ without any object which consists of two non Newtonian Fluids whose properties similar to polymers. The properties for fluid 1 Density $-1.3 \mathrm{gm} / \mathrm{cm}^{3}$ and Viscosity -5000 to $7000 \mathrm{cps}$ and for fluid 2 the Density- $1.1 \mathrm{gm} / \mathrm{cm}^{3}$ and Viscosity- $2250 \mathrm{cps}$.

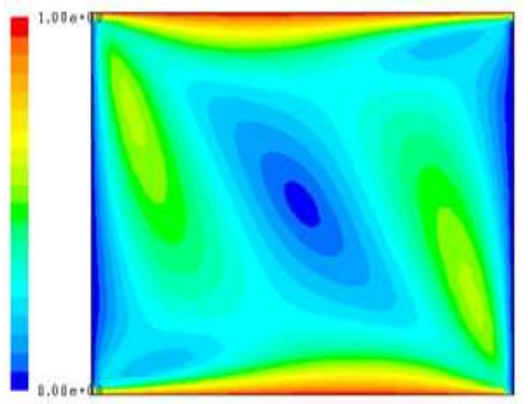

(a)

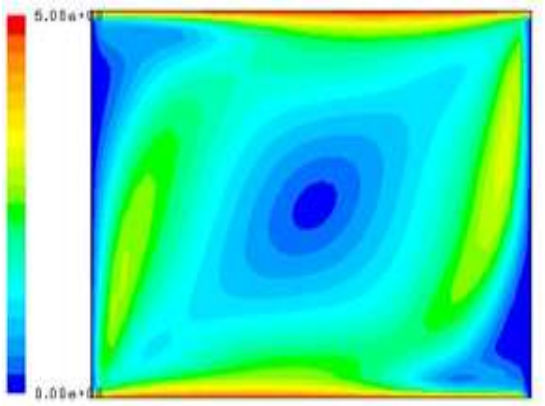

(b)

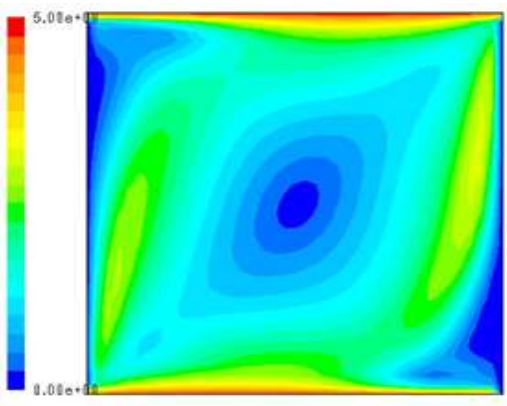

(c)

Figure. 2:-Streamline patterns from CFD simulations top and Bottom sliding wall

(a) $\mathrm{N}_{\mathrm{RE}}=145$ (b) $\mathrm{N}_{\mathrm{RE}}=727$ (c) $\mathrm{N}_{\mathrm{RE}}=1018$.

Case I: Square Lid Driven Cavity Flow with top and bottom plate moving

As the top and bottom plate moving with steady velocity mixing takes place inside the cavity. The average velocity inside the cavity is high when both top and bottom plates are moving than only top plate moves. The cavity box with both top and bottom plates are moving is simulated for different Reynolds number. From fig. 2 it's very clear that as Reynolds number increases, there is increase in the average velocity [2]. The contours of volume fraction of phase 1 for different Reynolds number is studied (Fig. 3). The mixing index as a function of Reynolds number and mixing time is tabulated in the table 1 . 


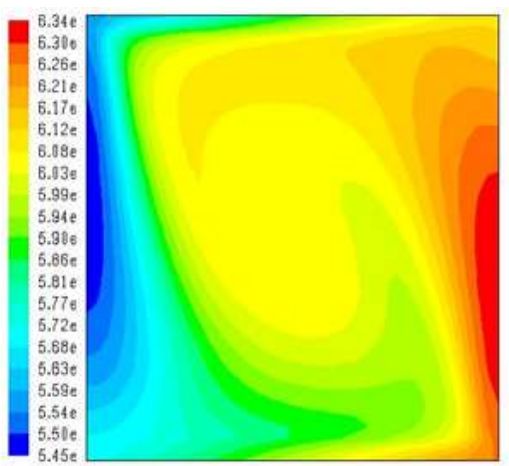

(a)
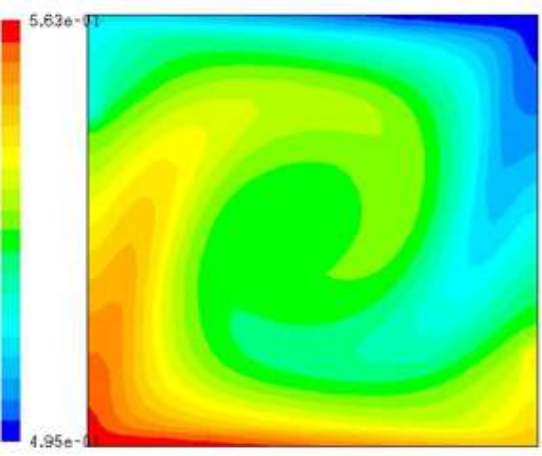

(b)

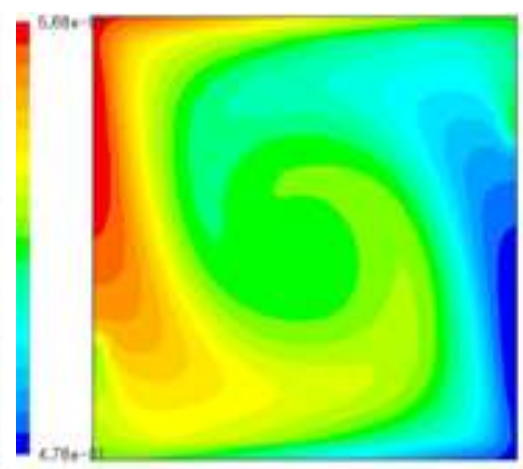

(c)

Figure.3 Contours of volume fraction (phase-1) simulations top and bottom sliding wall

(a) $\mathrm{N}_{\mathrm{RE}}=145$ (b) $\mathrm{N}_{\mathrm{RE}}=727$ (c) $\mathrm{N}_{\mathrm{RE}}=1018$

Table 1:-Mixing Index with respect to time at different Reynolds number for case I

\begin{tabular}{|c|l|l|l|l|l|l|l|l|l|l|}
\hline Sl.No. & \multicolumn{2}{l}{$\mathbf{N}_{\mathbf{R E}}=\mathbf{1 4 5}$} & \multicolumn{2}{l}{$\mathbf{N}_{\mathbf{R E}}=\mathbf{4 3 6}$} & \multicolumn{2}{l}{$\mathbf{N}_{\mathbf{R E}}=\mathbf{7 2 7}$} & \multicolumn{2}{l}{$\mathbf{N}_{\mathbf{R E}}=\mathbf{1 0 1 8}$} & \multicolumn{2}{l|}{$\mathbf{N}_{\mathbf{R E}}=\mathbf{1 3 0 9}$} \\
\hline & $\begin{array}{l}\text { Mixing } \\
\text { time, } \\
\text { sec }\end{array}$ & $\begin{array}{l}\text { Mixing } \\
\text { index }\end{array}$ & $\begin{array}{l}\text { Mixing } \\
\text { time, } \\
\text { sec }\end{array}$ & $\begin{array}{l}\text { Mixing } \\
\text { index }\end{array}$ & $\begin{array}{l}\text { Mixing } \\
\text { time, } \\
\text { sec }\end{array}$ & $\begin{array}{l}\text { Mixing } \\
\text { index }\end{array}$ & $\begin{array}{l}\text { Mixing } \\
\text { time, } \\
\text { sec }\end{array}$ & $\begin{array}{l}\text { Mixing } \\
\text { index }\end{array}$ & $\begin{array}{l}\text { Mixing } \\
\text { time, } \\
\text { sec }\end{array}$ & $\begin{array}{l}\text { Mixing } \\
\text { index }\end{array}$ \\
\hline 1. & 0 & 0 & 0 & 0 & 0 & 0 & 0 & 0 & 0 & 0 \\
\hline 2. & 100 & 0.1655 & 100 & 0.2328 & 100 & 0.2461 & 100 & 0.2492 & 100 & 0.2593 \\
\hline 3. & 300 & 0.5274 & 300 & 0.6196 & 300 & 0.6159 & 300 & 0.6077 & 300 & 0.6731 \\
\hline 4. & 400 & 0.5653 & 400 & 0.6561 & 400 & 0.6654 & 400 & 0.671 & 400 & 0.6901 \\
\hline 5. & 500 & 0.6593 & 500 & 0.7497 & 500 & 0.7686 & 500 & 0.7808 & 500 & 0.7921 \\
\hline 6. & 700 & 0.7412 & 700 & 0.8346 & 700 & 0.8547 & 700 & 0.8621 & 700 & 0.8797 \\
\hline 7. & 800 & 0.7683 & 800 & 0.8607 & 800 & 0.8864 & 800 & 0.8976 & 800 & 0.8904 \\
\hline 8. & 900 & 0.788 & 900 & 0.8863 & 900 & 0.9161 & 900 & 0.9256 & 900 & 0.9308 \\
\hline 9. & 1100 & 0.7962 & 1100 & 0.8947 & 1100 & 0.9284 & 1100 & 0.9416 & 1100 & 0.9537 \\
\hline 10. & 1200 & 0.8008 & 1200 & 0.901 & 1200 & 0.9366 & 1200 & 0.9421 & 1200 & 0.9541 \\
\hline 11. & 1300 & 0.8009 & 1300 & 0.9013 & 1400 & 0.9366 & 1400 & 0.9424 & 1400 & 0.9541 \\
\hline 12. & 1400 & 0.8009 & 1500 & 0.9013 & 1500 & 0.9366 & 1500 & 0.9429 & 1500 & 0.9544 \\
\hline
\end{tabular}

\section{Case II: Square Lid Driven Cavity with object on the centre of left and right wall:-}

Square lid driven cavity box of dimension $50 \mathrm{~cm}$ of length with solid object on the centre of left and right wall whose dimension is $1.25 \times 7.5 \mathrm{~cm}$ [Case II (A)]. The contours of volume fraction (Fig. 4) shows how the particle movies and the mixing pattern inside the cavity and which is used to find the mixing index (table 2). In order to reduce the dead zone (with respect to increase the mixing index at the corner) choosing a object whose dimension is one tenth of the cavity box size [Case II (B)] on the centre of left and right wall which shows good results than the previous one. The streamline patterns (Fig. 5) of phase 1 for different Reynolds number tells that as Reynolds number increases, there is increase in the mixing index which tabulated in Table 3 as well as its comparatively less than the case I.

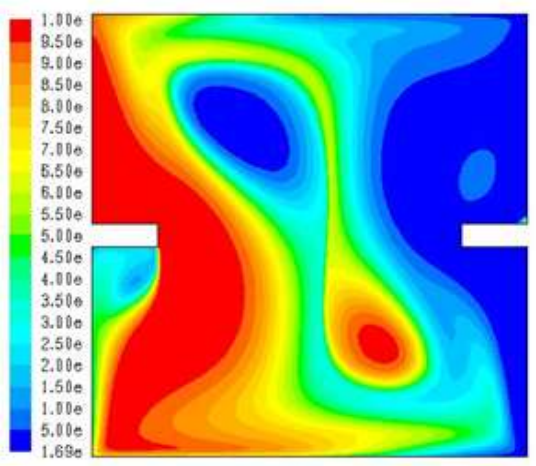

(a)

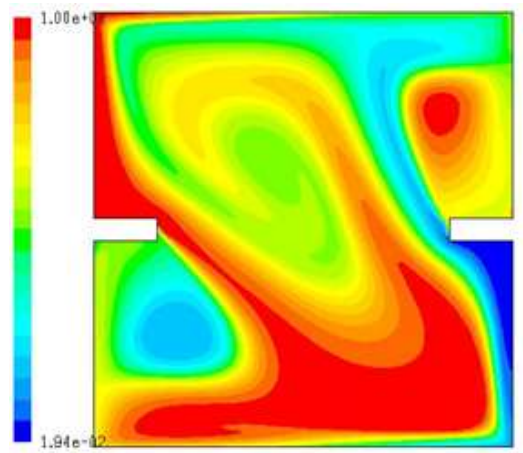

(b)

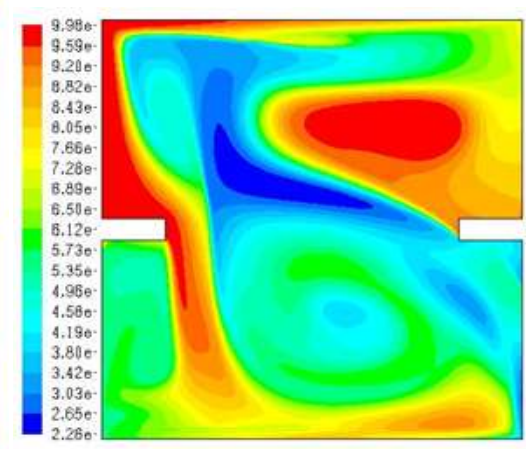

(c) 
Figure. 4:-Contours of volume fraction (phase-1) solid object on Left and right Stationary wall [Case II (A)] (a)

$$
\mathrm{N}_{\mathrm{RE}}=145 \text { (b) } \mathrm{N}_{\mathrm{RE}}=727 \text { (c) } \mathrm{N}_{\mathrm{RE}}=1309
$$

Table 2:-Mixing Index with respect to time at different Reynolds number for case II (A) with object dimension of $1.25 \times 7.5 \mathrm{~cm}$

\begin{tabular}{|l|l|l|}
\hline Sl.No & Reynolds Number & Mixing Index \\
\hline 1. & 145 & 0.26971 \\
\hline 2. & 436 & 0.32254 \\
\hline 3. & 727 & 0.39646 \\
\hline 4. & 1018 & 0.50372 \\
\hline 5. & 1309 & 0.5118 \\
\hline
\end{tabular}

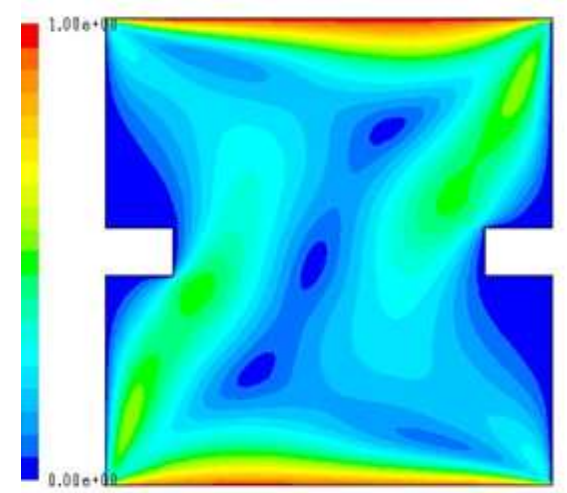

(a)

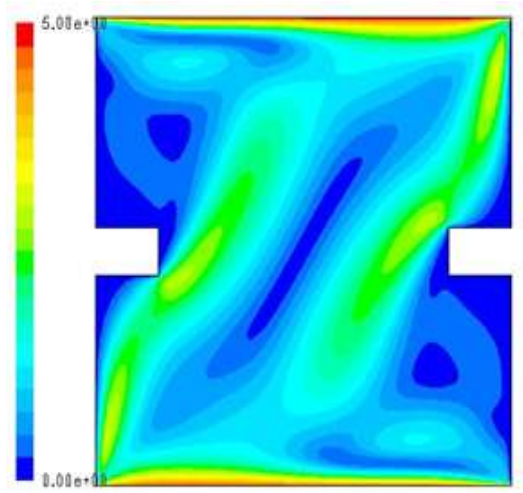

(b)

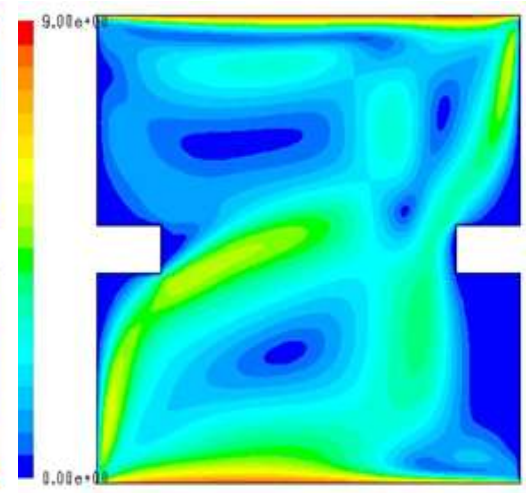

(c)

Figure. 5:-Streamline patterns from CFD simulations solid object on Left and right Stationary wall [Case II (B)] (a)

$$
\mathrm{N}_{\mathrm{RE}}=145 \text { (b) } \mathrm{N}_{\mathrm{RE}}=727 \text { (c) } \mathrm{N}_{\mathrm{RE}}=1309
$$

\begin{tabular}{|c|c|c|c|c|c|c|c|c|c|c|}
\hline SI No. & \multicolumn{2}{|l|}{$\mathrm{N}_{\mathrm{RE}}=145$} & \multicolumn{2}{|c|}{$N_{R E}=436$} & \multicolumn{2}{|c|}{$\mathrm{N}_{\mathrm{RE}}=727$} & \multicolumn{2}{|c|}{$\mathrm{N}_{\mathrm{RE}}=1018$} & \multicolumn{2}{|c|}{$N_{R E}=1309$} \\
\hline & $\begin{array}{l}\text { Mixing } \\
\text { time, sec }\end{array}$ & $\begin{array}{l}\text { Mixing } \\
\text { index }\end{array}$ & $\begin{array}{l}\text { Mixing } \\
\text { time, } \\
\text { sec }\end{array}$ & $\begin{array}{l}\text { Mixing } \\
\text { index }\end{array}$ & $\begin{array}{l}\text { Mixing } \\
\text { time, } \\
\text { sec }\end{array}$ & $\begin{array}{l}\text { Mixing } \\
\text { index }\end{array}$ & $\begin{array}{l}\text { Mixing } \\
\text { time, } \\
\text { sec }\end{array}$ & $\begin{array}{l}\text { Mixing } \\
\text { index }\end{array}$ & $\begin{array}{l}\text { Mixing } \\
\text { time, } \\
\text { sec }\end{array}$ & $\begin{array}{l}\text { Mixing } \\
\text { index }\end{array}$ \\
\hline 1. & 0 & 0 & 0 & 0 & 0 & 0 & 0 & 0 & 0 & 0 \\
\hline 2. & 100 & 0.0615 & 100 & 0.0817 & 100 & 0.1013 & 100 & 0.0976 & 100 & 0.0931 \\
\hline 3. & 200 & 0.0743 & 200 & 0.1188 & 200 & 0.1938 & 200 & 0.2313 & 200 & 0.2349 \\
\hline 4. & 400 & 0.1336 & 400 & 0.2228 & 400 & 0.3093 & 400 & 0.4246 & 400 & 0.4925 \\
\hline 5. & 600 & 0.2877 & 600 & 0.3595 & 600 & 0.5111 & 600 & 0.5606 & 600 & 0.6072 \\
\hline 6. & 900 & 0.4405 & 900 & 0.5185 & 900 & 0.6388 & 900 & 0.6517 & 900 & 0.7013 \\
\hline 7. & 1100 & 0.4866 & 1100 & 0.5388 & 1100 & 0.6679 & 1100 & 0.7258 & 1100 & 0.7468 \\
\hline 8. & 1200 & 0.4888 & 1200 & 0.5557 & 1200 & 0.6689 & 1200 & 0.7279 & 1200 & 0.7543 \\
\hline 9. & 1400 & 0.594 & 1400 & 0.5949 & 1400 & 0.6789 & 1400 & 0.729 & 1400 & 0.7555 \\
\hline 10. & 1500 & 0.5989 & 1500 & 0.5991 & 1500 & 0.6791 & 1500 & 0.731 & 1500 & 0.7576 \\
\hline
\end{tabular}

Table 3:-Mixing Index with respect to time at different Reynolds number for case II (B)

Case III:Square Lid Driven Cavity with object on the centre of top and bottom lid:-

Introducing the solid object on the centre of top and bottom moving lid whose dimension is $1.25 \times 7.5 \mathrm{~cm}$ [Case III (A)] and its contours (Fig. 6) will act like baffles which comparatively increase the mixing in the corner which quantitatively calculated as mixing index for different Reynolds Number (Table 4). The size of the object is increased whose dimension is one tenth of the cavity box size [Case III (B)] in order to increase the mixing. In Fig. 7 shows the flow field inside the cavity which explains the dead zone. The mixing index (Table 5) can be calculated from contours of volume fraction (Fig. 8). The Comparision of all the above cases is shown in the fig. 9 


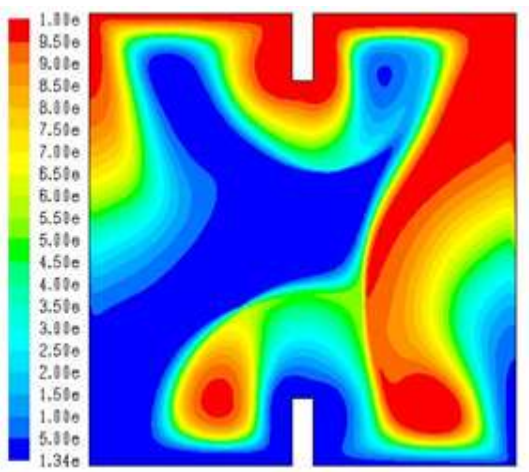

(a)

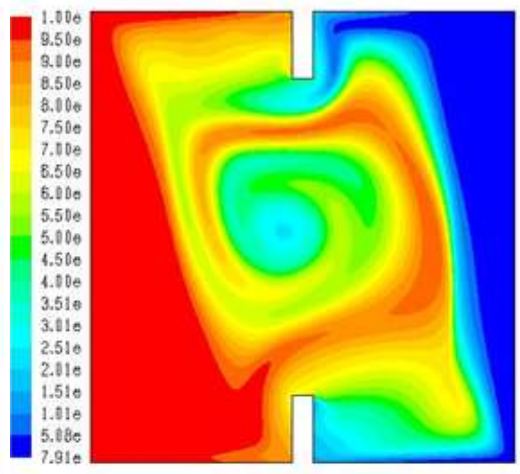

(b)

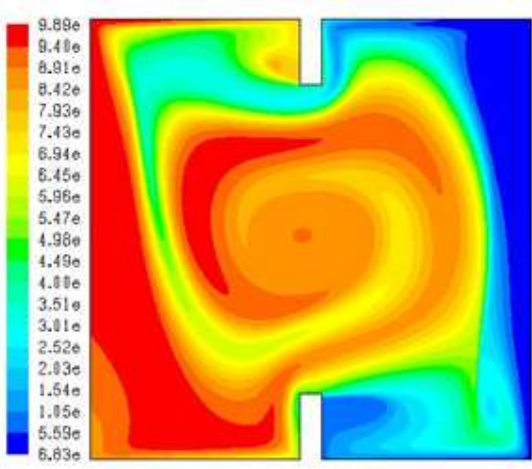

(c)

Figure. 6:-Contours of volume fraction (phase-1) simulations solid object $(1.25 \times 7.5 \mathrm{~cm})$ on top and bottom sliding wall [Case III (A)] (a) $\mathrm{N}_{\mathrm{RE}}=145$ (b) $\mathrm{N}_{\mathrm{RE}}=727$ (c) $\mathrm{N}_{\mathrm{RE}}=1309$.

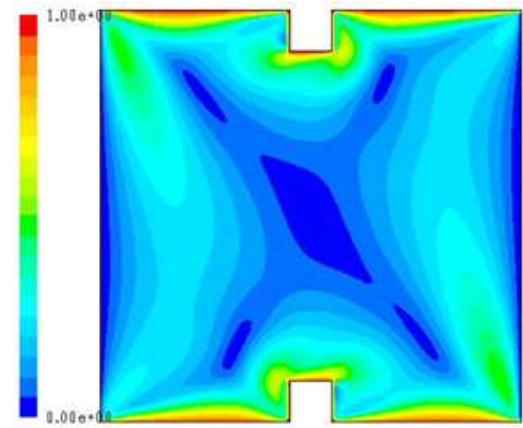

(a)

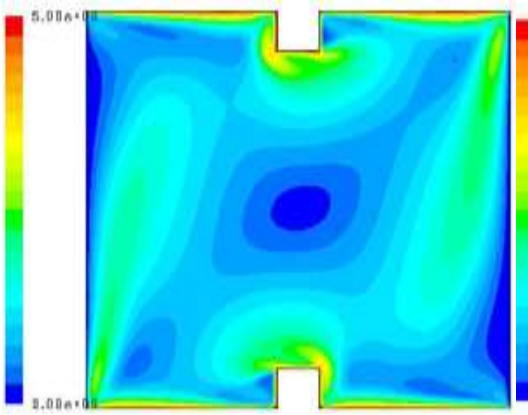

(b)

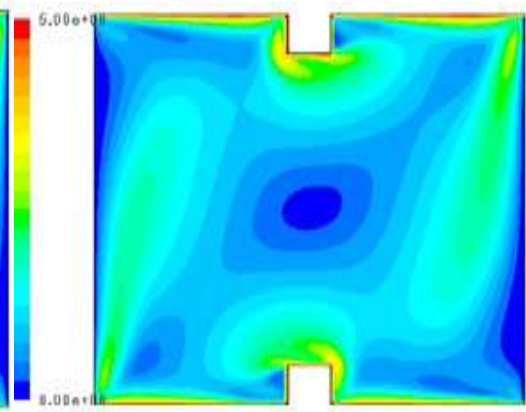

(c)

Figure. 7:-Streamline patterns from CFD simulations solid object on top and bottom sliding wall [Case III (B)]a) $\mathrm{N}_{\mathrm{RE}}=145$ (b) $\mathrm{N}_{\mathrm{RE}}=727$ (c) $\mathrm{N}_{\mathrm{RE}}=1309$

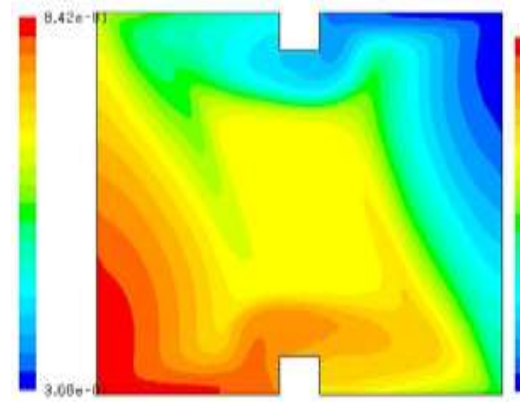

(a)

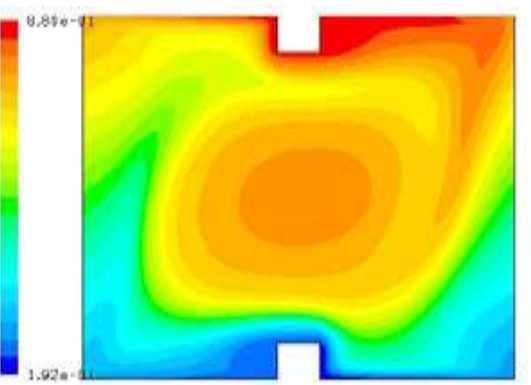

(b)

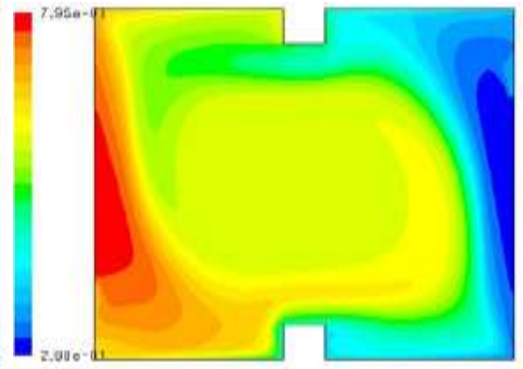

(c)

Figure. 8:-Contours of volume fraction (phase-1) simulations solid object on top and bottom sliding wall [Case III (B)] (a) $\mathrm{N}_{\mathrm{RE}}=145$ (b) $\mathrm{N}_{\mathrm{RE}}=727$ (c) $\mathrm{N}_{\mathrm{RE}}=1309$

Table 4:-Mixing Index with respect to time at different Reynolds number for case III (A) with object dimension of $1.25 \times 7.5 \mathrm{~cm}$

\begin{tabular}{|l|l|l|}
\hline Sl.No & Reynolds Number & Mixing Index \\
\hline 1 & 145 & 0.27479 \\
\hline 2 & 436 & 0.28688 \\
\hline 3 & 727 & 0.30279 \\
\hline 4 & 1018 & 0.31209 \\
\hline 5 & 1309 & 0.36072 \\
\hline
\end{tabular}




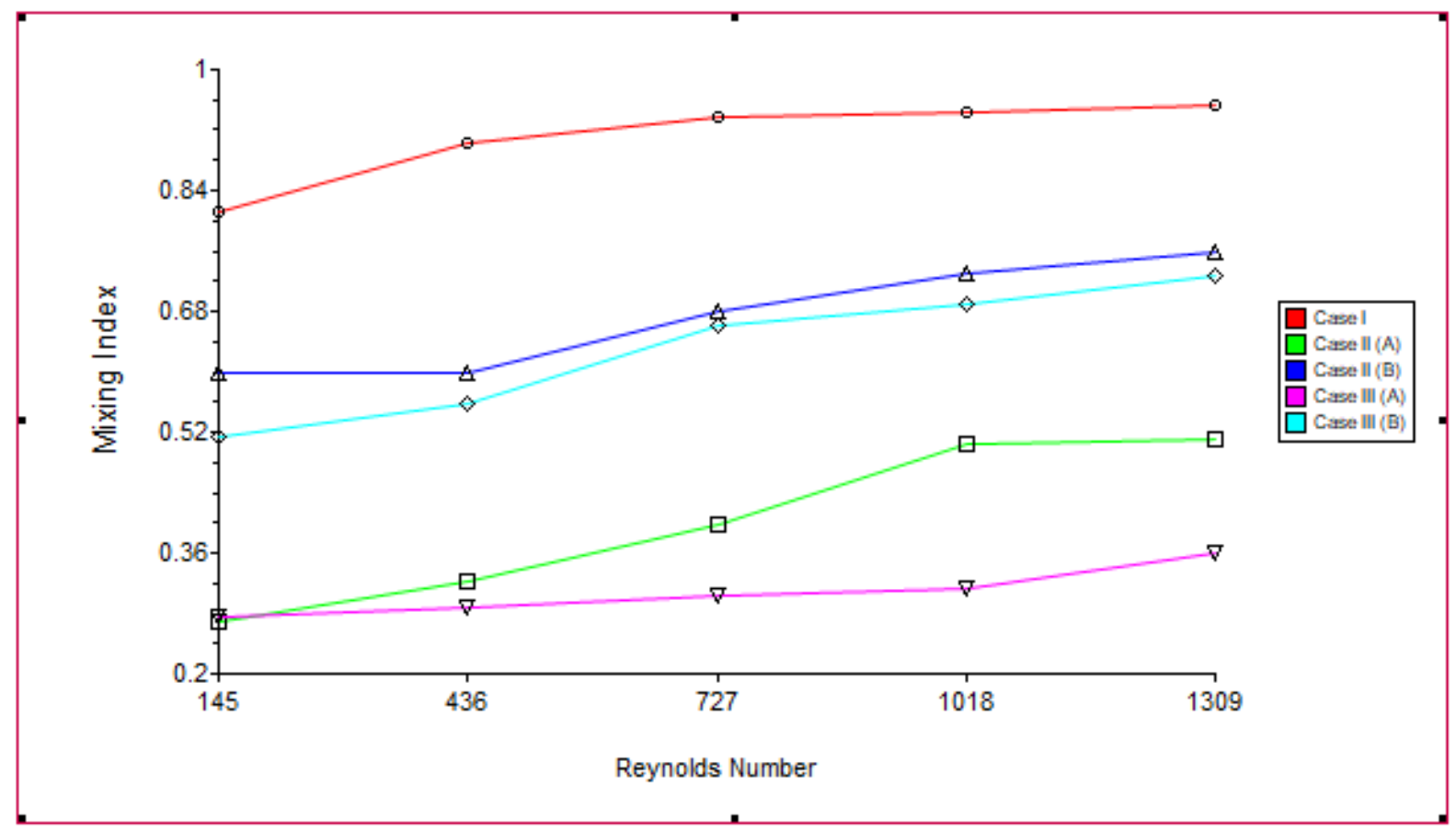

Figure. 9:-Comparision of all Cases

Table 5:-Mixing Index with respect to time at different Reynolds number for case III (B)

\begin{tabular}{|l|l|l|l|l|l|l|l|l|l|l|}
\hline Sl.No. & \multicolumn{2}{|l}{$\mathbf{N}_{\mathbf{R E}}=\mathbf{1 4 5}$} & \multicolumn{2}{l}{$\mathbf{N}_{\mathbf{R E}}=\mathbf{4 3 6}$} & \multicolumn{2}{l}{$\mathbf{N}_{\mathbf{R E}}=\mathbf{7 2 7}$} & \multicolumn{2}{l}{$\mathbf{N}_{\mathbf{R E}}=\mathbf{1 0 1 8}$} & \multicolumn{2}{l|}{$\mathbf{N}_{\mathbf{R E}}=\mathbf{1 3 0 9}$} \\
\hline & $\begin{array}{l}\text { Mixing } \\
\text { time, } \\
\text { sec }\end{array}$ & $\begin{array}{l}\text { Mixing } \\
\text { index }\end{array}$ & $\begin{array}{l}\text { Mixing } \\
\text { time, } \\
\text { sec }\end{array}$ & $\begin{array}{l}\text { Mixing } \\
\text { index }\end{array}$ & $\begin{array}{l}\text { Mixing } \\
\text { time, } \\
\text { sec }\end{array}$ & $\begin{array}{l}\text { Mixing } \\
\text { index }\end{array}$ & $\begin{array}{l}\text { Mixing } \\
\text { time, } \\
\text { sec }\end{array}$ & $\begin{array}{l}\text { Mixing } \\
\text { index }\end{array}$ & $\begin{array}{l}\text { Mixing } \\
\text { time, } \\
\text { sec }\end{array}$ & $\begin{array}{l}\text { Mixing } \\
\text { index }\end{array}$ \\
\hline 1 & 0 & 0 & 0 & 0 & 0 & 0 & 0 & 0 & 0 & 0 \\
\hline 2 & 300 & 0.1147 & 100 & 0.0587 & 100 & 0.0723 & 100 & 0.0812 & 100 & 0.0897 \\
\hline 3 & 400 & 0.1874 & 200 & 0.0995 & 300 & 0.1708 & 300 & 0.1898 & 300 & 0.1996 \\
\hline 4 & 600 & 0.2769 & 500 & 0.2999 & 600 & 0.3267 & 600 & 0.4057 & 600 & 0.4273 \\
\hline 5 & 900 & 0.4343 & 800 & 0.4324 & 900 & 0.511 & 900 & 0.6145 & 900 & 0.6301 \\
\hline 6 & 1200 & 0.4877 & 1100 & 0.4802 & 1300 & 0.5831 & 1200 & 0.6497 & 1200 & 0.678 \\
\hline 7 & 1500 & 0.5133 & 1500 & 0.5581 & 1500 & 0.6602 & 1500 & 0.6905 & 1500 & 0.7268 \\
\hline 8 & 1800 & 0.5594 & 1800 & 0.6614 & 1800 & 0.7102 & 1800 & 0.7302 & 1800 & 0.7578 \\
\hline
\end{tabular}

\section{Conclusion:-}

The comparison of all cases showsclearly that case I that is Square lid driven cavity box of dimension 50 X $50 \mathrm{~cm}$ without any object which has efficient mixing when compared to other cases. Then case II that is Square lid driven cavity box of dimension $50 * 50 \mathrm{~cm}$ with object on the centre of left and right wall whose dimension is $5 \times 5 \mathrm{~cm}$ which better mixing when compared to other cases other than cases. The mixing is very less due to formation of dead zones when the solid object size is decreased to dimension of $1.25 \times 7.5 \mathrm{~cm}$. The case II and case III comparatively gives same level of mixing when the size of solid object is one tenth of the cavity size. It's concluded that the mixing is far when there is no solid object in top and bottom plate moving with a steady motion in opposite direction.

\section{Acknowledgment:-}

The authors express their gratitude to Management of St Joseph's College of Engineering. 


\section{References:-}

1. BinXia, Da-Wen, Sun, "Applications of computational fluid dynamics (CFD) in the food industry: a review" Computers and Electronics in Agriculture 34, 5-24, (2002)

2. Charles-Henri, BruneauMazenSaad, "The 2D lid-driven cavity problem revisited" Computers \& Fluids 35, 326$348,(2006)$

3. ReyadOmari, "CFD Simulations of Lid Driven Cavity Flow at Moderate Reynolds Number" European Scientific Journal , 9, 22-35, (2013)

4. N.Alleborna, H.Raszilliera, F.Dursta, "Lid-driven cavity with heat and mass transport" International Journal of Heat and Mass Transfer 42, 833-853 (1999)

5. Gouillart, E., Thiffeault, J., and Finn, M.D. Topological mixing with ghost rods. Physical Review E, 73, 18(2006).

6. Shankar, P.N., and Deshpande, M.D. Fluid Mechanics in the driven cavity. Annual Review, Fluid Mechanics, 32, 93-136, (2000).

7. Chien, W.L., Rising, H., and Ottino, J.M. Laminar mixing and chaotic mixing in several cavity flows. Journal of Fluid Mechanics, 170, 355-377, (1986)

8. Vivian O'brien, "Unsteady Separation Phenomena in a Two-Dimensional Cavity" AIAA Journal 13, 415-425, (1975)

9. W.YSoh, John W, Goodrich, "Unsteady solution of incompressible Navier-Stokes equations" Journal of Computational Physics, 79, 113-134, (1988).

10. Iwatsu, R., J. M. Hyun and K. Kuwahara, "Numerical simulations of three dimensional flows in a cubic cavity with an oscillating Lid," Journal of Fluids Engineering, 115, pp. 680-686 (1993).

11. Ottino, J. M. and C. W. Leong, "Experiments on mixing due to chaotic advection in a cavity," J. Fluid Mech., 209, 463-499 (1989).

12. C. W. Leong and J. M. Ottino, "Increase in regularity by polymer addition during chaotic mixing in twodimensional flows" Phys. Rev. Lett. 64, $874-888,1990$

13. Grillet, A.M., B. Yang, B. Khomami and E.S.G. Shaqfeh, "Modeling of viscoelastic lid driven cavity flow using finite element simulations," J. Non-Newtonian Fluid Mech., 88, 99-131 (1999).

14. Anderson, P. D., "Computational analysis of distributive mixing," Ph. D thesis, Eindhoven University of Technology, Department of Mechanical Engineering, Netherlands (1999).

15. Anderson, P. D., O. S. Galaktionov, G. W. M. Peters, F. N. Van De Vosse, and H. E. H. Meijer, "Mixing of non- Newtonian fluids in a time-periodic cavity flows," J. Non-Newtonian Fluid Mech., 93, 265-286 (2000).

16. Anderson, P.D., O. S. Galaktionov, G. W. M. Peters, F. N. Van De Vosse and H. E. H. Meijer, "Analysis of mixing in three-dimensional time-periodic cavity flows," J. Non-Newtonian Mech., 386, 149-169 (1999).

Nomenclature

p - Static pressure

$\rho g$ - is the gravitational force.

$\eta$ - Non-Newtonian viscosity

D - Rate-of-deformation tensor

$\gamma$ - Shear rate

$\mathrm{u}$ - Velocity 